\title{
Stopping ability in younger and older adults: Behavioral and event-related potential
}

\author{
Shulan Hsieh ${ }^{1,2,3}$ • Yu-Chi Lin ${ }^{1}$
}

Published online: 28 November 2016

(C) Psychonomic Society, Inc. 2016

\begin{abstract}
This study examines age-related differences in inhibitory control as measured by stop-signal performance. The participants were 24 adults aged 20-30 years and 24 older adults aged $61-76$ years. The task blocks were pure choice reaction-time blocks, global stop-signal blocks (with an auditory stop signal), and selective stop-signal blocks (with valid and invalid stop signals). There was a decline in reactive inhibitory control for the older group reflected by greater stopsignal reaction times and reduced P3 peak amplitudes in both global and selective stop-signal task blocks. The decreased reactive inhibitory control might result from speed-accuracy tradeoffs. Conversely, no age-related decline in proactive inhibitory control was observed. This was reflected by slower response times (RTs) and reduced $\mathrm{P} 3$ peak amplitudes during GO trials in blocks with stop-signals relative to those in blocks of pure choice reaction-time tasks, and in which the RT and amplitude differences were similar between groups. The results further show age-related compensation responses associated with proactive inhibition, such as increased activation at the frontal site among older participants, resulting in no differences in P3 peak amplitudes between electrode sites, and smaller differences at the Fz site than other sites compared with younger adults. For older adults, the P3 peak amplitude
\end{abstract}

Shulan Hsieh

psyhs1@mail.ncku.edu.tw

1 Cognitive Electrophysiology Laboratory: Control, Aging, Sleep, and Emotion (CASE), Department of Psychology, National Cheng Kung University, 1 University Road, Tainan 701, Taiwan

2 Institute of Allied Health Sciences, National Cheng Kung University, Tainan, Taiwan

3 Department and Institute of Public Health, National Cheng Kung University, Tainan, Taiwan at the Fz site was significantly correlated with the RT of proactive inhibitory control. This shows that larger RT differences were associated with larger reductions in P3 peak amplitudes in the stop-signal blocks relative to the pure choice blocks. These results appear to support age-related compensation hypotheses.

Keywords Reactive inhibitory control · Proactive inhibitory control · Stop-signal reaction time · Compensation .

Scaffolding theory of aging and cognition

\section{Introduction}

In daily life, people often need to refrain from responding or acting when in danger or when a readied response is no longer required. Such adaptive behavior is one of the crucial survival skills of living organisms. Therefore, it is important to examine if this crucial behavior is maintained, diminished, or modified with advancing age. A conventional paradigm for evaluating response inhibition in the laboratory is the stop-signal paradigm (Logan \& Cowan, 1984). In the conventional stopsignal paradigm, participants are typically presented with a stimulus requiring a rapid left- versus right-hand (choice) response. In some trials, a stop signal, indicating that the response should be withheld, is presented occasionally and unpredictably a few hundred milliseconds (e.g., 150-600 ms) following stimulus onset. In this field, most studies of aging have investigated inhibition using either the conventional or extended version of the stop-signal paradigm. However, results have been mixed. While some studies have suggested age-related stop-signal inhibition deficits (e.g., Bedard, Nichols, Barbosa, Schachar, Logan, \& Tannock, 2002; Kleerekooper, van Rooij, van den Wildenberg, de Leeuw, Kahn, \& Vink, 2016; Kramer, Humphrey, Larish, \& Logan, 
1994; Van de Laar, Wildenberg, Boxtel, \& Molen 2011), others have found either no age-related decline (e.g., Kray, Kipp, \& Karbach, 2009) or only a specific deficit (e.g., Anguera \& Gazzaley, 2012).

Several factors might have contributed to these mixed results. One may be related to task demand. For example, researchers have compared global and selective stop-signal task conditions to examine age-related decline in inhibitory control while assuming that different degrees of task demand would be tapped (Bedard et al., 2002; Van de Laar et al. 2011; see also Coxon, Van Impe, Wenderoth, \& Swinnen 2012 and Coxon, Goble, Leunissen, Van Impe, Wenderoth, \& Swinnen 2016, who used the Slater-Hammel version of the stop-signal task to study selective stopping in aging ${ }^{1}$ ). The global stop-signal task (GST) requires participants to stop all responses when one and only one stop signal occurs, while the selective stop-signal task (SST) paradigm involves two stop signals: one indicates that participants should stop their responses, and the other indicates that they should ignore the signal and continue to respond. ${ }^{2}$ Studies have shown that the stopping efficacy in SST blocks relative to GST blocks exhibited a more pronounced decline with respect to age (withinstudy comparison: Van de Laar et al. 2011; across-study comparison: Bedard et al., 2002; Williams, Ponesse, Schachar, Logan, \& Tannock, 1999). In some stop-signal studies, including the present study, the selective stop-signal involves discrimination between more than one presented stop signal (i.e., at the perceptual level, with one valid stop signal and an invalid one; Sharp et al., 2010; Van de Laar et al. 2010; 2011). In contrast, some stop-signal studies refer to the discrimination between choices of responses (i.e., at the motor level: some responses should be inhibited, but not others; De Jong, Coles, \& Logan 1995; van de Laar et al., 2010).

Previous research comparing the stopping performance between the GST and SST conditions has been based on at least two main motivations. First, the GST does not capture the adaptive control process as often as required in everyday-life scenarios (Aron, 2011). On the other hand, the SST requires additional discrimination of stop signals from ignored signals, which may be closer to an everyday life scenario (Bedard et al., 2002). As such, the stopping (i.e., reactive inhibitory) processing in the SST conditions may be more practically valid and more sensitive to aging than the GST conditions. Second, the stop trials in the GST conditions may mix together processing associated with attentional capture of an auditory stop signal and processing associated with response

\footnotetext{
${ }^{1}$ Another version of the stop-signal paradigm involves infrequent presentation of a stop cue before an anticipated response (Slater-Hammel, 1960). The Slater-Hammel version of the stop task is becoming popular and has the potential to increase our knowledge of reactive inhibitory control (e.g., see Coxon, Stinear, \& Byblow, 2007, 2009; Stinear, Coxon, \& Byblow, 2009).

2 The GST and SST task blocks are analogous with the "original" and "controlled" stop-signal tasks by Sharp et al. (2010).
}

inhibition. To disentangle the two types of processing, previous research (e.g., Sharp et al., 2010; van de Laar et al., 2010) has suggested adding a control condition such as the SST to incorporate the presentation of an invalid stop signal that should be ignored (i.e., ignore stop-signal trials or continue trials). In addition to these two main motivations, the aim of the present study is to elucidate whether age-related differences in stop processing are similar (suggesting a general deficit) or different (suggesting a specific deficit) between GST and SST blocks.

Another potential factor contributing to the mixed results may be the type of inhibitory control used. Some studies have suggested that inhibitory control can be divided into reactive and proactive inhibition (for a review, see Aron, 2011; Aron \& Verbruggen, 2008; Vink, Kahn, Raemaekers, van den Heuvel, Boersma, \& Ramsey, 2005). Reactive inhibitory control efficacy refers to the duration of the stop-signal reaction time (SSRT). Shorter SSRTs indicate more efficient inhibition (Verbruggen \& Logan, 2008). Proactive inhibitory control refers to a slower RT to the GO trials in the task blocks using insertion of a stop signal, such as in the GST and SST blocks, compared to those GO trials in the pure choice RT (CRT) task blocks (i.e., anticipation of stopping; Kleerekooper et al., 2016 ${ }^{3}$; Vink et al., 2005). Unfortunately, only a few studies that have examined age-related inhibition efficacy have disentangled these two types of inhibitory control (however, see Kleerekooper et al. (2016), Smittenaar et al. (2015), and Van de Laar et al. (2011). These studies have shown that while there is an age-related decline in reactive inhibitory control (Kleerekooper et al., 2016; Van de Laar et al. 2011), there was not necessarily an age-related decline in proactive inhibitory control (Kleerekooper et al., 2016; Smittenaar et al. 2015; Vink et al., 2005; Zandbelt \& Vink, 2010; but see Van de Laar et al. 2011 for a different result demonstrating an agerelated decline in proactive control). Hence, research investigating age-related response inhibition should consider this factor.

A third factor may be associated with age-related compensatory responses. For example, Kleerekooper and colleagues (2016) discovered an overall hyperactivation in the right inferior frontal gyrus (rIFG) related to proactive inhibitory control in older adults (indicating age-related neural compensation), although behaviorally, they did not exercise more proactive inhibition strategies than younger adults. Similar findings regarding age-related compensation have been reported in other research using other types of inhibition paradigms (e.g., Hsieh \& Fang, 2012; Hsieh, Liang, \& Tsai, 2012; Hsieh \& Lin, 2014; Hsieh, Wu, \& Tang 2016a, b). These findings seem to

\footnotetext{
${ }^{3}$ Note that there is another index that represents proactive control efficacy, as suggested by Kleerekooper et al. (2016). The RTs of the GO trials are compared between various blocks of stop-signal probabilities (e.g., the block using $0 \%$ stop signal vs. various blocks using $>0 \%$ stop signals (e.g., $17 \%$ vs. $20 \%$ and vs. $25 \%$ vs. $33 \%$ in Kleerekooper et al. (2016)).
} 
be consistent with the neural compensation hypothesis, such as the revised Scaffolding Theory of Aging and Cognition (STAC-r; Reuter-Lorenz \& Park, 2014; see also STAC in Park \& Reuter-Lorenz, 2009), which proposed the term "compensatory scaffolding" to delineate "the engagement of supplementary neural circuitry that provides additional computational support required by an aging brain to preserve cognitive function in the face of localized or global neurofunctional decline."

Therefore, by considering the aforementioned three possible factors, we aimed to examine if there are age-related differences reflected in behavioral performance and brain responses (including reactive and proactive control efficacies) and if there is any age-related brain compensation associated with age-related inhibition control. We used the event-related potential (ERP) approach because of its exquisite temporal resolution and the multidimensional aspects of its data (i.e., the amplitude, latency, and distribution of every ERP component), which may help clarify the contradictory age-related decline in inhibitory control results based on behavioral data. In particular, the seemingly equivalent behavioral RT performance between the younger and older groups may involve underlying differences in the responses of ERP components, reflecting age-related brain compensation.

To examine ERP correlates of the reactive inhibitory control, we targeted the stop-signal N1 and P3 components because we used an auditory stop signal, which reportedly evokes larger N1 and P3 components for successful stops than for failed stops (Bekker, Kenemans, Hoeksma, Talsma, \& Verbaten, 2005; De Jong, Coles, Logan, \& Gratton, 1990; Kok, Ramautar, De Ruiter, Band, \& Ridderinkhof, 2004). These ERP components were distributed mostly over the fronto-central region of the scalp, such as at the $\mathrm{FCz}$ or $\mathrm{Cz}$ site. The stop-signal N1 has been hypothesized to reflect the sensitivity to the physical parameters of sound stimuli (Näätänen \& Picton 1987). As a result, successfully directing attention to sound stimuli (such as by successfully stopping after a stop signal) may add a further negative component to the obligatory N1 component (Näätänen \& Michie 1979; Parasuraman, 1980). In contrast, failure to selectively attend to a stop signal may attenuate the N1 component. The stopsignal P3 has been hypothesized to reflect stopping processes (i.e., the efficacy of motor inhibition; De Jong et al., 1990; Kok et al., 2004; Polich, 2007). Therefore, if the elderly suffered from a generalized deficit in reactive inhibitory control, we would expect a reduced or delayed stop-signal N1 or P3 in both GST and SST blocks compared to younger adults. Otherwise, there would be deterioration in one of either the GST or the SST blocks.

To determine if there is age-related decline in proactive inhibitory control, we compared the $\mathrm{N} 1$ and $\mathrm{P} 3$ components evoked during GO trials (GO N1 and GO P3) in task blocks featuring stop-signal insertions (GST and SST blocks) with those evoked during GO trials in pure CRT task blocks. The GO trials involved visual stimuli, which have been suggested to evoke N1 amplitudes over the posterior electrode sites (e.g., P7/P8, PO7/PO8, or PO5/PO6), with larger amplitudes for attended rather than unattended stimuli (Vogel \& Luck, 2000). We also targeted the GO P3 signal, since the amplitudes over the parietal-central electrode sites (e.g., $\mathrm{Cz}$ and $\mathrm{Pz}$ sites) are modulated by the stimulus intensity (Donchin, Karis, Bashore, Coles, \& Gratton, 1986a; Donchin, Kramer, \& Wickens, 1986b; Jodo \& Inoue, 1990; Polich \& Kok, 1995) or demands on "perceptual-central" resources (Donchin et al., 1986b; Kramer \& Spinks, 1991). Accordingly, larger GO N1 and GO P3 amplitudes would be expected in the CRT blocks than in the GST and SST blocks, which would reflect a proactive inhibition process. If there were an age-related difference in proactive inhibition, there would be differences among the three task blocks that are further modulated by age.

Finally, we determined whether there is age-related ERP compensation associated with reactive or proactive inhibitory control among older adults. To achieve this goal, we targeted the GO P3 and stop-signal P3 to observe whether there were age-related differences in the midline scalp topography (Fz, $\mathrm{Cz}$, and $\mathrm{Pz}$ ) during proactive and reactive inhibitory control. In the event of an age-related topographic difference, we would correlate the behavioral performance with the corresponding ERP modulations at the electrodes of interest to clarify if it reflects an age-related compensation effect (Cabeza \& Dennis, 2012) or a de-differentiation effect (Li \& Lindenberger, 1999; see Heuninckx, Wenderoth, \& Swinnen, 2008 for the suggestion).

\section{Method}

\section{Participants}

Twenty-four younger adults (11 females; age range, 20-30 years; mean age, $23.04 \pm 2.52$ [standard deviation] years) and 24 older adults ${ }^{4}$ (13 females; age range, $61-76$ years; mean age, $66.29 \pm 3.91$ years) participated in this experiment. The mean numbers of years of education in the two groups were $15.54 \pm 1.22$ years and $13.79 \pm 2.22$ years, respectively (see Table 1). All participants were screened for cognitive impairment using the Mini-Mental State Examination (MMSE; Folstein, Folstein, \& McHugh, 1975; 25-30 points $=$ normal $; 21-24$ points $=$ mild dementia $; 14-20$ points $=$ moderate dementia; and $\leq 13$ points $=$ severe dementia) and for depression using the Beck Depression Inventory (BDI-II; Beck, Steer, Ball, \& Ranieri, 1996; cut-off = 13). Mean

\footnotetext{
${ }^{4}$ There were originally 26 older adults being recruited, but two of them were excluded from the analyses due to their excessive commission errors on the ignored signal trials.
} 
Table 1 Participant characteristics

\begin{tabular}{llll}
\hline & $\begin{array}{l}\text { Young } \\
(N=24)\end{array}$ & $\begin{array}{l}\text { Old } \\
(N=24)\end{array}$ & $\begin{array}{l}\text { Young } \\
\text { vs. old }\end{array}$ \\
\hline Gender (F/M) & $11 / 13$ & $13 / 11$ & -- \\
Age $(\mathrm{M} \pm \mathrm{SD}$; year) & $23.04 \pm 2.52$ & $66.29 \pm 3.91$ & $p<.01$ \\
Age range (year) & $20-30$ & $61-76$ & -- \\
Education (M $\pm \mathrm{SD} ;$ year) & $15.54 \pm 1.22$ & $13.79 \pm 2.22$ & $p<.05$ \\
MMSE (M $\pm \mathrm{SD})$ & $29.25 \pm 1.05$ & $28.21 \pm 1.29$ & $p<.05$ \\
MoCA $(\mathrm{M} \pm \mathrm{SD})$ & $27.42 \pm 2.02$ & $26.04 \pm 2.65$ & $\mathrm{Ns}$ \\
BDI-II $(\mathrm{M} \pm \mathrm{SD})$ & $3.33 \pm 2.90$ & $5.41 \pm 3.79$ & $p<.05$ \\
\hline
\end{tabular}

F/M female/male, $M$ mean, $S D$ standard deviation, $M M S E$ Mini-Mental State Examination, $M o C A$ Montreal Cognitive Assessment, BDI-II Beck Depression Inventory

MMSE scores were $29.25 \pm 1.05$ for the younger group and $28.21 \pm 1.29$ for the older group. ${ }^{5}$ Mean BDI-II scores were $3.33 \pm 2.90$ and $5.41 \pm 3.79$, respectively. In addition to the screening tests, all participants were evaluated for general cognitive ability using the Montreal Cognitive Assessment (MoCA; Nasreddine et al., 2005). Mean MoCA scores were $27.42 \pm 2.02$ for the younger group and $26.04 \pm 2.65$ for the older group. All participants provided written informed consent, and the study protocol was approved by the Institutional Review Board of the National Cheng Kung University Hospital, Taiwan. All participants were paid NT\$500-\$1,000 (US\$15-\$30) for approximately $3 \mathrm{~h}$ of participation.

\section{Equipment and stimulus}

The stop-signal program was generated using E-Prime 1.0 software (Psychology Software Tools, Pittsburgh, PA, USA) installed on a PC-compatible computer. The stimuli were presented on a 17-in. CRT screen. Participants were seated in a comfortable chair in a sound-attenuated room facing the computer screen at a distance of approximately $1 \mathrm{~m}$. The participants' responses to the GO stimuli were registered via a keyboard.

The GO stimuli consisted of a white letter "O" or " $\mathrm{X}$ " $(1.2$ $\times 1.2 \mathrm{~cm} ; 0.68^{\circ}$ visual angle) presented in the center of the screen against a dark gray background. The participants were instructed to press the "/" button using a finger on their right hand when the "O" was presented; they were also instructed

\footnotetext{
5 Although there were significant differences between the two age groups on the MMSE and BDI-II scores, we did not find that these factors interacted with the reported statistical results. Furthermore, we correlated all participants' MMSE and MoCA scores with their overall RTs and SSRTs, and none of the correlations reached statistical significance (all $p<.05$ ). Therefore, the findings of age-related differences in inhibitory control could not solely be attributed to the MMSE and MoCA scores.
}

to press the " $\mathrm{z}$ " button using a finger on their left hand when the " $X$ " was presented. The stimulus-response mapping was counterbalanced between the participants. The stop signals were sound (either $500 \mathrm{~Hz}$ or $1,000 \mathrm{~Hz}$ ) delivered through an earphone lasting for $30 \mathrm{~ms}$.

\section{Design and procedure}

The participants first provided their demographic information and completed consent forms. They then completed two screening tests (i.e., the MMSE \& BDI-II) and the MoCA. Individuals who passed both screening tests were then invited to participate in the formal stop-signal experiment. There were three types of experimental task blocks (participants were made aware of what each block would consist of). The first type was a CRT block in which all trials (100 total) contained GO stimuli. Each GO trial consisted of a white fixation point that persisted for $500 \mathrm{~ms}$ followed by a GO stimulus that persisted for $1,250 \mathrm{~ms}$ or until the participant responded. Next, the dark gray background was presented for a random duration between 250 and $750 \mathrm{~ms}$. The second type was a GST block of 100 trials, repeated four times. The probability for stop signals was $25 \%$; participants needed to withhold their responses as soon as they heard the sound (either $500 \mathrm{~Hz}$ or $1,000 \mathrm{~Hz}$ ). The response requirement for the GO trials (the remaining $75 \%$ of the trials) was the same as that in the CRT block. The delay between the GO stimulus onset and the stop signal, referred to as the stopsignal delay (SSD), was $225 \mathrm{~ms}$ in the first trial of the practice block. It was dynamically adjusted after valid stop trials throughout the experiment as a function of the stopping performance of the participant. Upon successful stopping, the SSD on the subsequent stop trial was increased by $25 \mathrm{~ms}$; a failure to stop resulted in a $25-\mathrm{ms}$ decrease in SSD with the next stop trial. The tracking algorithm (Levitt, 1971) was set to ensure 50\% failed inhibits, which yielded accurate estimates of stop-signal RTs (Band, Van Der Molen, \& Logan, 2003). The third type was an SST block consisting of 100 trials, repeated eight times. Two kinds of stop signals were used in the SST blocks: stop and ignored stop. The participants were required to discriminate between the two stop signals and inhibit their responses upon hearing one stop signal (e.g., $1,000 \mathrm{~Hz}$ ) while ignoring the other stop signal (e.g., 500 $\mathrm{Hz}$ ). The frequencies associated with the two sounds were counterbalanced between the participants. The stop-signal trials requiring participants to stop were referred to as "valid" stop-signal trials (12.5\%), and the stop trials in which the stop signal should be ignored were referred to as "invalid" stop-signal trials (12.5\%; e.g., Van de Laar et al. 2011). 


\section{Electrophysiological recordings}

The electroencephalographic activity of the participants was continuously recorded using a Neuroscan (El Paso, TX, USA) SynAmp2 amplifier and a Q-Cap (AgCl-32 electrode cap; Neuroscan, Inc.) with 32 scalp electrodes. The vertical electro-oculogram (EOG) was recorded using four electrodes, two placed $2 \mathrm{~cm}$ above and two placed $2 \mathrm{~cm}$ below the left eye, and the horizontal EOG was recorded using two electrodes, one placed $1 \mathrm{~cm}$ external to the outer canthus of each eye. A ground electrode was placed on the forehead. The electrodes were initially referenced online to the left mastoid and offline to the average of the left and right mastoids. The electrode impedances were maintained at less than $5 \mathrm{k} \Omega$. The EEG and EOG signals were amplified and digitized at a sampling rate of $500 \mathrm{~Hz}$; online high- and low-pass filters with cutoffs at $0.01 \mathrm{~Hz}$ and $50 \mathrm{~Hz}$, respectively, were used. Ocular artifacts associated with blinks were corrected by the ocular reduction command offered by the Neuroscan software (Neuroscan, Inc.) and were further removed via an algorithm (Neuroscan software) that rejected any epoch if the signal was below $-50 \pm 50 \mu \mathrm{V}$, if the drift of the EEG from baseline exceeded $-50 \pm 50 \mu \mathrm{V}$, or if the $\mathrm{A} / \mathrm{D}$ converts became saturated. The number of artifact trials for each participant and each condition was on average between 6 and $12 \%$.

\section{Behavioral analysis}

Four sets of analyses were performed on both the younger and the older adults. In one, median RTs and proportions of errors (response errors and omission errors) associated with the no-signal GO trials of the CRT, GST, and SST blocks were calculated. The no-signal GO RT reflects the completion time for GO trials when there was no need to discriminate between stop signals (i.e., to stop or ignore in the SST blocks) or to stop (i.e., in the GST blocks). In another, the SSDs, SSRTs, and percentages of successful inhibits associated with stop-signal trials were calculated. The SSRTs were estimated using the integration method (Band et al., 2003; Logan \& Cowan, 1984; Verbruggen \& Logan, 2009a). For each SSD, the probability of responding to stop signals was determined. If an SSD of $50 \mathrm{~ms}$ resulted in a $25 \%$ error rate (stop-signal respond [failed inhibit] trials), then the end of the stop process should be at a point equal to $25 \%$ of the GO RT distribution. If this point was $300 \mathrm{~ms}$, then the observed SSRT would be $(300-50)=250 \mathrm{~ms}$. This procedure was repeated for each SSD (condition-based) for each participant. The mean SSRT was the average of these SSRTs estimated at various points. In a third analysis, the median failed inhibit RTs for the GST and the SST blocks were determined. Finally, the median RT for the ignored stopsignal trials for the SST blocks was determined. The failed inhibit RT is the RT for trials in which the stop signal was presented, but participants failed to withhold the response. The ignored stop-signal RT is the RT for trials in which an ignored signal was presented; therefore, stopping was not required. A log transformation was applied to RT data to reduce age-related variability, even though their distributions were normal.

A series of repeated-measures analyses of variance (ANOVAs) were conducted. Post-hoc analyses following the significant effect of task-block type (three levels) was performed using Tukey tests. When two (or more) factors in an ANOVA showed statistically significant interactions, the simple main effects were determined. This involves examining the effect of one factor at the level of another factor. That is, the data were split for each level of one factor, and one-way ANOVAs were performed. Like any other one-way ANOVA with more than two levels, after a significant $F$ is found, a post-hoc Tukey test was conducted to find out which pair (or pairs) of means was (were) statistically different. To overcome the inflation of a Type 1 error when a series of simple main effect analyses were conducted, we used the Bonferroni correction to adjust the $p$ value. In addition, we followed the pooled error term approach advised by Howell (2010, pp. 483-488) for the choice of error term in the simple main effect test.

Event-related potential (ERP) analysis: Stimulus-locked ERP

Epochs lasting $1,022 \mathrm{~ms}$ beginning $200 \mathrm{~ms}$ before the onset of a correct GO event or a stop signal were extracted. Because there was a short interval between the GO and stop-signal stimuli, the evoked ERP responses overlapped in time, possibly distorting the stop-signal-locked ERP average waveforms (Woldorff, 1993). We used the adjacent response filter technique to estimate and correct for the overlap (Schmajuk, Liotti, Busse, \& Woldorff, 2006; Woldorff, 1993). This procedure involved subtracting the convolution of the GO ERPs with the stop-signal delay distribution from the stop-signal ERPs. More specifically, for each condition separately, we shifted the averaged waveforms time-locked to the GO stimuli across the 25- to 950-ms GO-to-stop-signal interval range preceding the stop signals, weighted by the number of actual occurrences at each interval. The adjacent-response-corrected stop-signal waveforms and the GO ERPs were baseline-corrected with a prestimulus interval of $200 \mathrm{~ms}$.

Group average stimulus-locked ERPs were inspected to identify appropriate time windows for extraction of peak amplitude and latency for GO and stop-signal N1 and P3 components and sites where components were maximal. 
The N1 component associated with the visual GO stimulus was measured at P7 and P8 where visual N1 was largest. ${ }^{6}$ The P3 component associated with the visual GO stimulus was measured at $\mathrm{Fz}, \mathrm{Cz}$, and $\mathrm{Pz}$ to explore the midline scalp topography of the GO P3. The N1 component associated with the stop-signal stimulus was measured at $\mathrm{Cz}$ where the auditory N1 was maximal. The P3 component associated with the stop-signal stimulus was also measured at $\mathrm{Fz}, \mathrm{Cz}$, and $\mathrm{Pz}$ to explore the midline scalp topography of the stop-signal P3. The N1 peak amplitude was defined as the most negative point between 100 and $300 \mathrm{~ms}$ after event onset (GO-locked or stopsignal-locked). The P3 peak amplitude was defined as the most positive point between 300 and $700 \mathrm{~ms}$ after event onset (GO-locked or stop-signal-locked).

\section{Relationship between ERP and behavioral effects of proactive and reactive inhibition}

The peak amplitudes are retrieved if there is an agerelated topographic difference in the ERP correlates of proactive and reactive inhibition in the GO P3 and stopsignal P3 (the most positive point between 300 and $700 \mathrm{~ms}$ after event onset). They would then be correlated with the corresponding behavioral RT effect using simple linear correlation and regression implemented in an $\mathrm{R}$ function. For example, if there was an age-related topographic difference during proactive inhibitory control, then the differences in P3 amplitude at the electrode of interest would be correlated with the corresponding RT differences (in GO trials between the stop-signal task blocks collapsed over the GST and SST task blocks and pure choice RT task blocks).

\section{Results}

\section{Behavioral data}

Performance on the no-signal GO trial: Proactive inhibition

See Table 2 for the behavioral results of the GO trials and Table 3 for the results of the analyses of variance (ANOVAs).

\section{Reaction times}

Results of a two-way ANOVA (age [younger, older] $\times$ taskblock type [CRT, GST, SST]) of the log-transformed RTs

\footnotetext{
${ }^{6}$ The Woody's (1967) filter technique was used for latency-jitter correction of GO N1
}

revealed that only the main effects of age and block type were significant; no significant interaction between the two factors was found. Tukey post-hoc tests on block type revealed that the log-transformed RTs during the no-signal GO trials were slower in both the GST $(2.74 \pm 0.10)$ and SST $(2.74 \pm 0.11)$ blocks than in the CRT $(2.65 \pm 0.09)$ blocks (all $p$ values $<.01$ ) (Table 3 ). As a result, the logtransformed RT data suggest that although the elderly performed generally slower than younger adults, their proactive control, as manifested by the slower log-transformed RTs during the no-signal GO trials in the GST and SST blocks than in the CRT blocks, was similar.

\section{Proportion of error: Error and omission error}

Results of a similar two-way ANOVA revealed that older adults exhibited more omission errors than younger adults $(3.41 \% \pm 4.89 \%$ vs. $0.68 \% \pm 1.37 \%)$. Neither group showed any significant differences in omission errors as a function of block type. On the other hand, neither group showed any significant differences in errors, and both showed significantly more errors in the CRT blocks than in the GST or SST blocks $(2.58 \% \pm 3.01 \%$ vs. $0.96 \% \pm 0.96 \%$ and $1.26 \% \pm 1.18 \%$, respectively).

\section{Performance on stop-signal trials: Reactive inhibition}

See Table 2 for the behavioral results of the stop-signal trials and Table 3 for the results of the ANOVAs.

\section{Stop-signal reaction time}

Results of the ANOVA of SSRT data revealed that older adults' SSRTs were longer than those of younger adults, and both age groups exhibited longer SSRTs in the SST blocks than in the GST blocks.

\section{Percentage of successful inhibits}

The percentage of successful inhibits was nearly $50 \%$ in both age groups. However, stopping success was higher among the older adults than the younger adults $(53.90 \% \pm$ $4.58 \%$ vs. $50.65 \% \pm 2.90 \%$ ). In addition, the proportion of successful inhibits was higher in the SST blocks than in the GST blocks $(53.11 \% \pm 4.59 \%$ vs. $51.44 \% \pm$ $3.49 \%)$.

\section{Failed inhibit reaction time}

A two-way ANOVA (age [younger, older] $\times$ task-block [GST, SST]) revealed that older adults had significantly longer failed inhibit RTs than younger adults. No other significant main effects or interactions were found. 
Table 2 Median reaction time (RT; ms) and percentage of error (error and omission; \%) associated with GO trials in the pure choice reaction task (CRT), global stop-signal task (GST), and selective stop-signal task (SST) blocks; Mean stop-signal RT (SSRT; ms), and percentage of successful inhibits (\%) associated with stop-signal trials in the GST and
SST blocks; Median failed inhibit RT (ms) associated with stop-signal trials in the GST and SST blocks, and ignore stop-signal RT (ms) and percentage of omission (\%) in the SST blocks, in each age group (standard deviation in parentheses)

\begin{tabular}{|c|c|c|c|c|c|c|}
\hline & \multicolumn{2}{|l|}{ CRT } & \multicolumn{2}{|l|}{ GST } & \multicolumn{2}{|l|}{ SST } \\
\hline & Young & Old & Young & Old & Young & Old \\
\hline GO RT & $395.29(60.20)$ & $522.81(79.57)$ & $482.54(91.63)$ & $654.40(105.77)$ & $459.96(88.87)$ & $668.13(107.43)$ \\
\hline GO Error & $2.38(3.13)$ & $2.79(3.01)$ & $1.07(0.92)$ & $0.85(1.04)$ & $1.53(1.31)$ & $1.00(1.02)$ \\
\hline GO Omission & $0.71(1.43)$ & $1.96(2.22)$ & $0.78(0.98)$ & $5.11(6.86)$ & $0.56(1.70)$ & $3.17(4.20)$ \\
\hline SSRT & - & -- & $264.12(30.13)$ & $292.19(55.68)$ & $279.05(32.07)$ & $325.48(58.32)$ \\
\hline$\%$ Inhibit & -- & -- & $50.08(2.47)$ & $52.79(3.95)$ & $51.21(3.28)$ & $55.01(5.06)$ \\
\hline Failed inhibit RT & -- & -- & $407.21(75.45)$ & $575.25(101.27)$ & $401.56(70.52)$ & $593.41(100.87)$ \\
\hline Ignore stop-signal RT & -- & -- & - & - & $576.88(127.59)$ & 799.05 (129.92) \\
\hline Ignore stop-signal Error & -- & -- & -- & -- & $2.08(2.08)$ & $1.04(1.27)$ \\
\hline Ignore stop-signal Omission & -- & -- & -- & -- & $1.50(1.96)$ & $17.36(14.07)$ \\
\hline
\end{tabular}

\section{Invalid (ignore) stop-signal RT}

This set of analyses focused only on the invalid stopsignal RTs in the SST blocks. Results of a one-way ANOVA revealed that older adults exhibited longer RTs than younger adults. Significant interactions were not found.

\section{Percentage of errors and omissions in the invalid (ignore) stop-signal trials}

Comparing the proportions of errors and omissions between the two age groups, results revealed that older adults exhibited more errors and omissions than younger adults.

\section{ERP data}

GO trials in the CRT, GST, and SST blocks: Proactive inhibition

Brain waveforms exhibited during the GO trials in the CRT, GST, and SST blocks for the two age groups at the P7 and P8 sites (for examining N1), and the $\mathrm{Fz}, \mathrm{Cz}$, and $\mathrm{Pz}$ sites (for examining P3 and respective topographic maps of the P3 peak amplitudes) are shown in Figs. 1 and 2. Statistical results of the ANOVAs are shown in Tables 4 and 5 .

\section{GO-N1 peak amplitude and latency}

Results of a three-way ANOVA (age $\times$ task-block type $\times$ electrode site $[\mathrm{P} 7, \mathrm{P} 8]$ ) of the $\mathrm{N} 1$ peak amplitudes recorded during

Table 3 Results of the analysis of variance (ANOVA) for the behavioral data (log-transformed reaction time (RT), error and omission) on GO, stopsignal, and ignore trials

\begin{tabular}{|c|c|c|c|c|}
\hline \multicolumn{5}{|l|}{ GO trial } \\
\hline \multicolumn{2}{|l|}{ Age $\times$ Block } & GO RT & GO Error & GO Omission \\
\hline Age & $F(1,46)$ & $76.90 * *$ & $0.07(.79)$ & $17.14 * *$ \\
\hline Block & $F(2,92)$ & $38.80 * *$ & $11.98 * *$ & $2.93(.053)$ \\
\hline CRT vs. GST & $q(92,3)$ & ** & $* *$ & -- \\
\hline CRT vs. SST & $q(92,3)$ & ** & $* *$ & -- \\
\hline GST vs. SST & $q(92,3)$ & -- & -- & -- \\
\hline Age $\times$ Block & $F(2,92)$ & $1.82(.20)$ & $0.92(.40)$ & $2.59(.08)$ \\
\hline \multicolumn{5}{|l|}{ Stop-signal trial } \\
\hline Age $\times$ Block & & SSRT & Successful inhibits rate & Failed inhibit RT \\
\hline Age & $F(1,46)$ & $5.82 *$ & $14.99 * *$ & $63.89 * *$ \\
\hline Block & $F(1,46)$ & $13.31 * *$ & $5.55 *$ & $0.28(.60)$ \\
\hline Age $\times$ Block & $F(1,46)$ & $3.04(.08)$ & $0.59(.45)$ & $1.01(.32)$ \\
\hline \multicolumn{5}{|c|}{ Ignore stop-signal trial } \\
\hline Age & & Ignore RT & Ignore Error & Ignore Omission \\
\hline Age & $F(1,46)$ & $35.73 * *$ & $4.38 *$ & $29.92 * *$ \\
\hline
\end{tabular}

Note: $q(92,3) .05=3.38 ; q(92,3) .01=4.24$

$* \mathrm{p}<.05 ; * * \mathrm{p}<.01$. Values in parentheses indicate the original $\mathrm{p}$ value

$C R T$ choice reaction task, GST global stop-signal task, SST selective stop-signal task, SSRT stop-signal reaction time 
the GO trials showed larger N1s in the CRT blocks than in the GST or SST blocks and at the P8 site than at the P7 site (all $p<$ .01 ; see Table 4 ). Main effects of age and interactions with age were not found.

Results of a three-way ANOVA of N1 peak latency showed delayed N1s among the older adults compared to the younger adults and in the GST blocks compared to the CRT blocks ( $p$ $<.05$; see Table 4). Interactions with age were not observed.

\section{GO-P3 peak amplitude and latency}

Results of a three-way ANOVA (age $\times$ task-block type $\times$ electrode site $[\mathrm{Fz}, \mathrm{Cz}, \mathrm{Pz}]$ ) of $\mathrm{P} 3$ peak amplitudes showed larger P3s in the CRT blocks than in the GST or SST blocks. Simple main effect tests on the interaction between age and electrode site showed that only younger adults and not older adults exhibited a significant main effect of electrode site (younger: $7.31 \pm 3.47 \mu \mathrm{V}$ for $\mathrm{Cz}$ and $7.84 \pm 3.41 \mu \mathrm{V}$ for $\mathrm{Pz}$, which are greater than $5.32 \pm 2.23 \mu \mathrm{V}$ for Fz vs. older: $6.15 \pm 3.31 \mu \mathrm{V}$, $6.50 \pm 2.65 \mu \mathrm{V}$, and $6.40 \pm 2.46 \mu \mathrm{V}$, respectively).

Results of a three-way ANOVA of P3 peak latencies showed delayed P3s among older adults compared to younger

\section{P7}
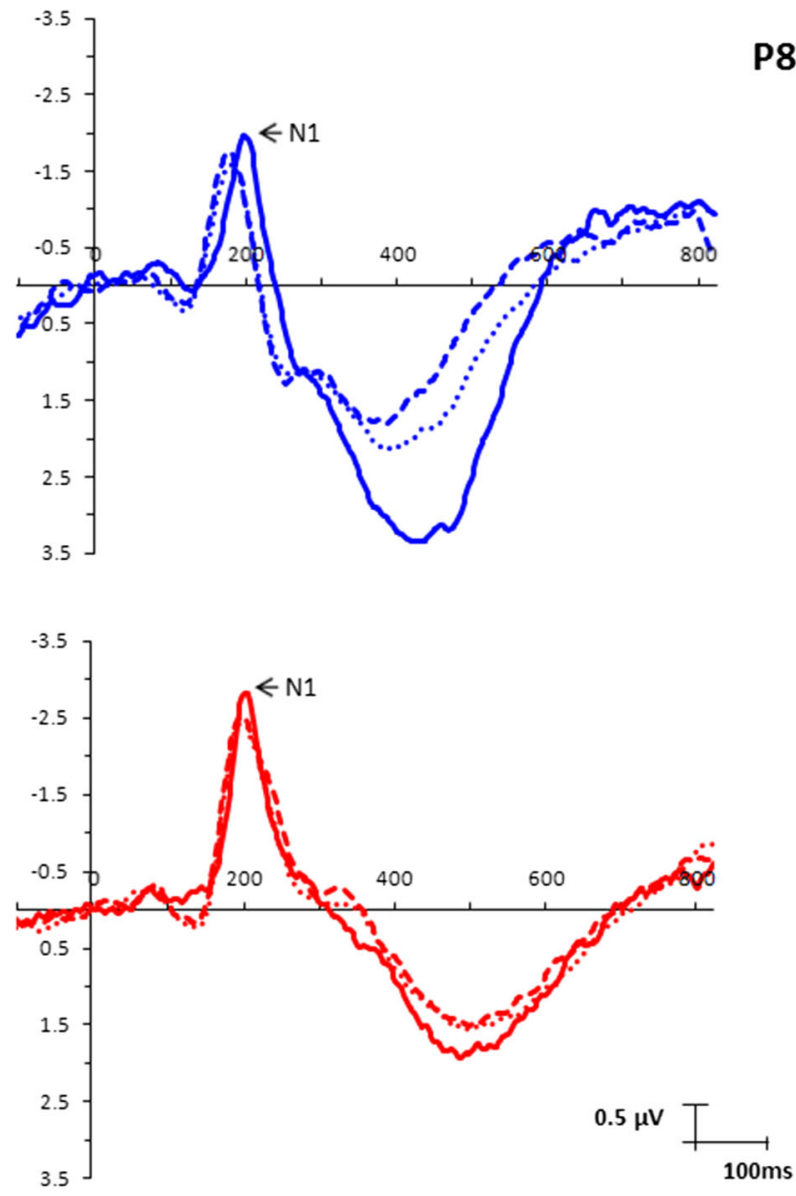

Fig. 1 Grand average event-related potential (ERP) waveforms time locked to the onset of GO stimulus for younger (blue) and older (red) adults in the choice reaction time (CRT), global stopping task (GST), and

P8 adults (496.19 $\pm 61.16 \mathrm{~ms}$ vs. $403.82 \pm 58.61 \mathrm{~ms})$. In addition, simple effect tests on the two-way interaction between age and electrode site revealed that younger adults' $\mathrm{P} 3$ peak latencies at the $\mathrm{Pz}$ site were earlier than at the $\mathrm{Fz}$ and $\mathrm{Cz}$ sites $(391.00 \pm$ $49.95 \mathrm{~ms}$ vs. $405.17 \pm 62.89 \mathrm{~ms}$ and $415.29 \pm 59.67 \mathrm{~ms}$, respectively). Among older adults, they were earlier at the Fz site than at the $\mathrm{Cz}$ and $\mathrm{Pz}$ sites $(476.24 \pm 59.17 \mathrm{~ms}$ vs. $508.10 \pm 65.42 \mathrm{~ms}$ and $504.24 \pm 53.26 \mathrm{~ms}$, respectively).

Correlations between proactive control effect of GO-P3 peak amplitude and $R T$

The proactive inhibition effect reflected in the $\mathrm{P} 3$ peak amplitudes did not differ significantly among electrode sites (Fz, $\mathrm{Cz}$, and $\mathrm{Pz}$ ) for older adults. This implies an increased proactive inhibition effect of $\mathrm{P} 3$ peak amplitudes at the Fz site. To further clarify whether the increased $\mathrm{Fz}$ activation in older adults represented a de-differentiation or compensation effect, we examined the relationship between P3 peak amplitudes at the Fz site and the RTs of proactive inhibitory control. The correlation coefficient was significant and negative for the older group (Pearson's $r=-0.47, p<.05$; see Fig. 5 for the
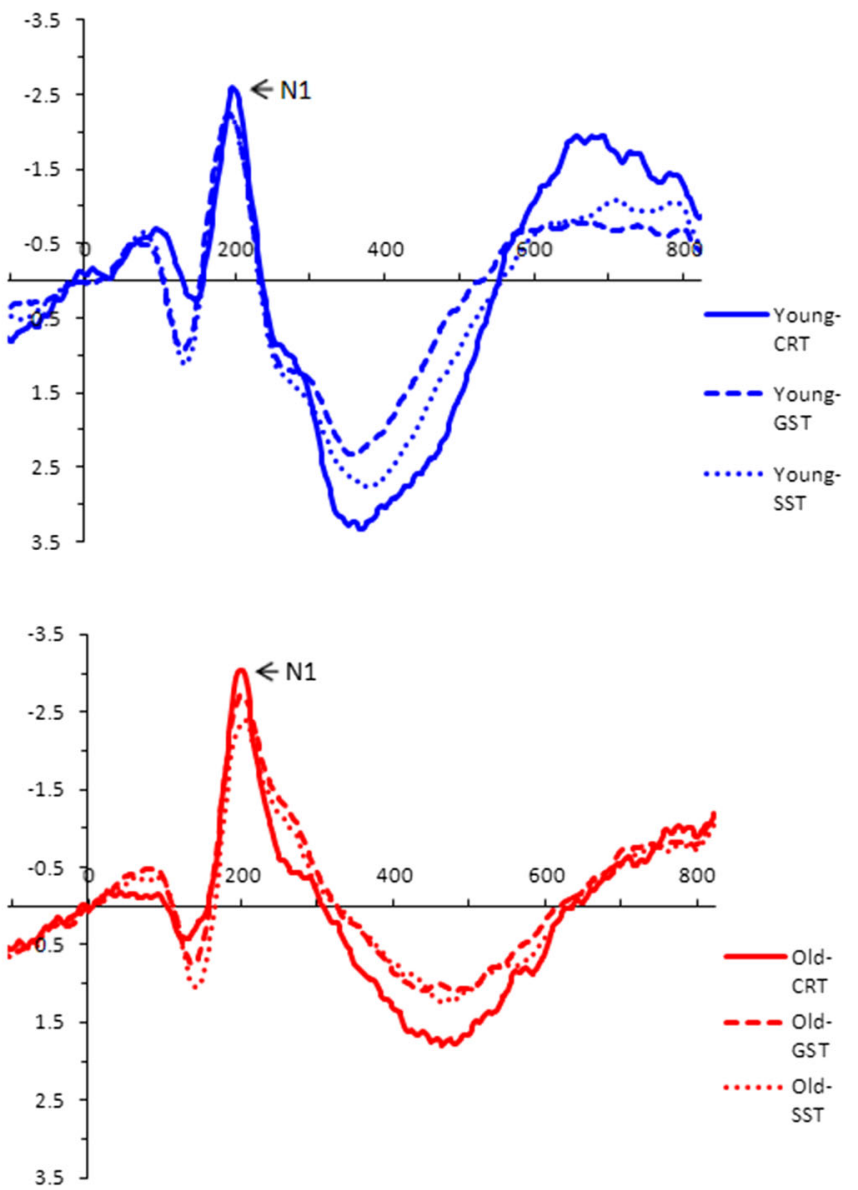

selective stopping task (SST) blocks at the P7 and P8 electrode sites. The waveforms underwent Woody's (1967) adaptive filter technique 

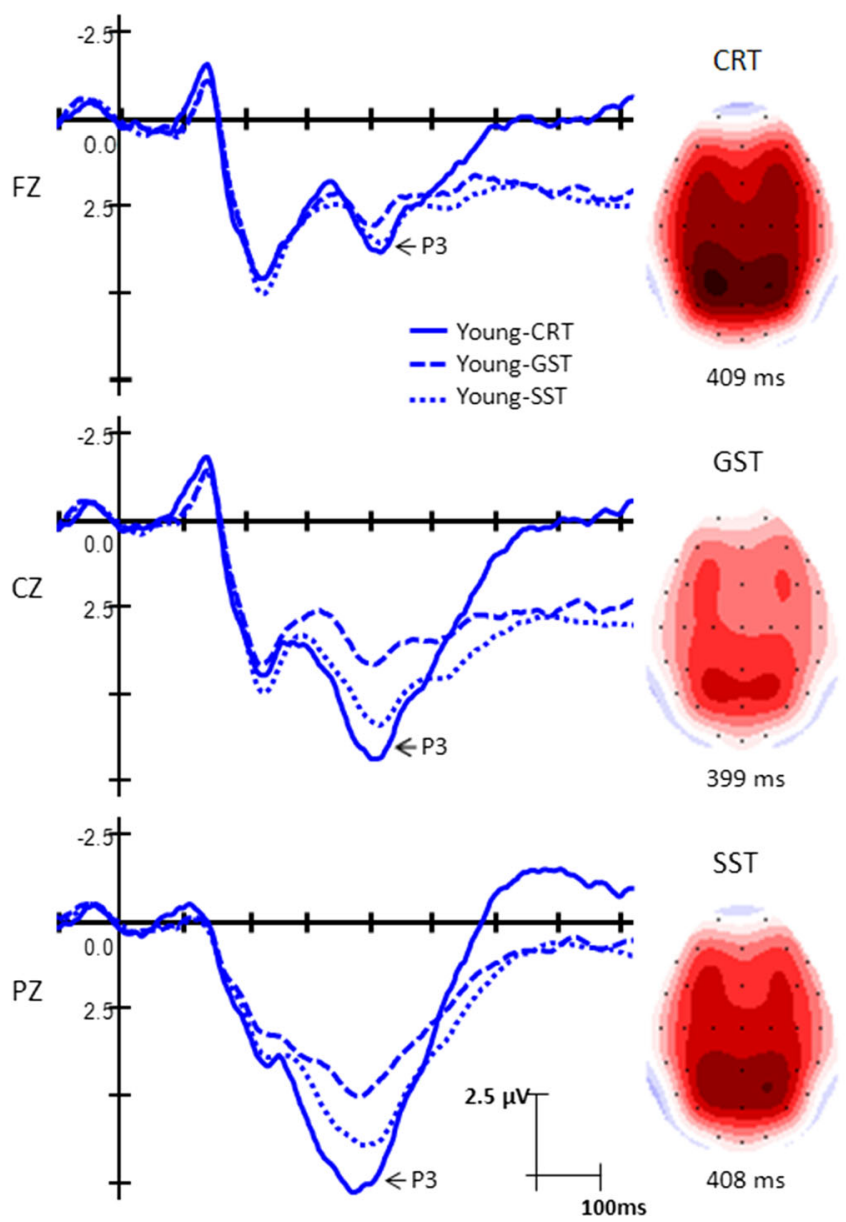

Fig. 2 Grand average event-related potential (ERP) waveforms time locked to the onset of GO stimulus for younger (blue; left column) and older (red; right column) adults in the choice reaction time (CRT), global stopping task (GST), and selective stopping task (SST) blocks at the Fz,

Table 4 Results of the analysis of variance (ANOVA) for the eventrelated potential (ERP) data of the N1 component at the P7 and P8 sites (amplitude and latency) on the GO trials

\begin{tabular}{llll}
\hline Age $\times$ Block $\times$ Site $(\mathrm{P} 7$, P8) & Go N1 amplitude & Go N1 latency \\
\hline GO N1 & & & \\
Age & $F(1,46)$ & $1.26(.27)$ & $11.81 * *$ \\
Block & $F(2,92)$ & $10.90 * *$ & $3.77 *$ \\
CRT vs. GST & $q(92,3)$ & $* *$ & $*$ \\
CRT vs. SST & $q(92,3)$ & $* *$ & -- \\
GST vs. SST & $q(92,3)$ & -- & -- \\
Age $\times$ Block & $F(2,92)$ & $.004(1)$ & $1.30(.28)$ \\
Site & $F(1,46)$ & $7.73 * *$ & $2.14(.16)$ \\
Age $\times$ Site & $F(1,46)$ & $0.07(.79)$ & $0.06(.81)$ \\
Block $\times$ Site & $F(2,92)$ & $0.78(.46)$ & $0.58(.56)$ \\
Age $\times$ Block $\times$ Site & $F(2,92)$ & $0.19(.83)$ & $0.20(.82)$ \\
\hline
\end{tabular}

$* \mathrm{p}<.05 ; * * \mathrm{p}<.01$. Values in parentheses indicate the original $\mathrm{p}$ value CRT choice reaction task, GST global stop-signal task, SST selective stopsignal task, SSRT stop-signal reaction time

$q(92,3) .05=3.38 ; q(92,3) .01=4.24$
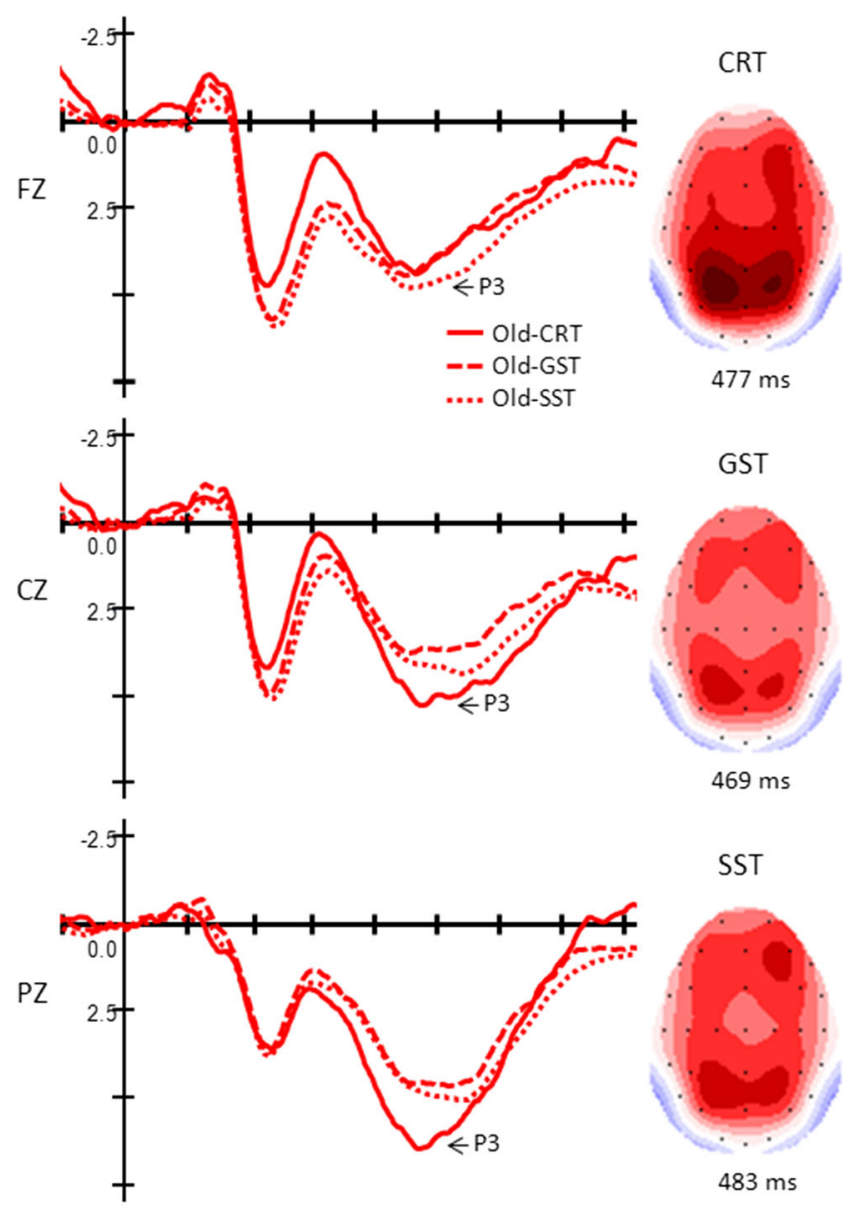

$\mathrm{Cz}$, and Pz electrode sites. The topographic maps are shown for younger (left column) and older (right column) adults at the P3 peak latencies in the corresponding conditions (CRT, GST, and SST)

scatterplot with fitted simple regression lines). This indicates that larger RT differences (reflecting proactive inhibitory control) were associated with larger reductions in P3 peak amplitudes in the stop-signal blocks relative to the pure choice blocks.

\section{Stop-signal trials: successful versus failed inhibit trials} in the GST and SST blocks: Reactive inhibition

Brain waveforms and respective topographic maps of the P3 peak amplitudes recorded during successful and failed inhibit trials for the two age groups are shown in Fig. 3 for the GST blocks and in Fig. 4 for the SST blocks. Statistical results of the ANOVAs are shown in Tables 6 and 7.

\section{Stop-signal N1 peak amplitude and latency}

Results of a three-way ANOVA (age $\times$ task-block type $\times$ stoptrial type [successful inhibit, failed inhibit]) of the N1 peak 
Table 5 Results of the analysis of variance (ANOVA) for the eventrelated potential (ERP) data of the $\mathrm{P} 3$ component at the $\mathrm{Fz}, \mathrm{Cz}$, and $\mathrm{Pz}$ sites (amplitude and latency) on the GO trials

\begin{tabular}{|c|c|c|c|}
\hline \multicolumn{2}{|c|}{ Age $\times$ Block $\times$ Site $(F Z, C Z, P Z)$} & \multirow[t]{2}{*}{ Go P3 amplitude } & \multirow[t]{2}{*}{ Go P3 latency } \\
\hline GO P3 & & & \\
\hline Age & $F(1,46)$ & $0.59(.45)$ & $63.85 * *$ \\
\hline Block & $F(2,92)$ & $36.96 * *$ & $1.42(.26)$ \\
\hline CRT vs. GST & $q(92,3)$ & $* *$ & -- \\
\hline CRT vs. SST & $q(92,3)$ & $* *$ & -- \\
\hline GST vs. SST & $q(92,3)$ & -- & -- \\
\hline Age $\times$ Block & $F(2,92)$ & $1.91(.19)$ & $0.53(.59)$ \\
\hline Site & $F(2,92)$ & $10.60 * *$ & $8.97 * *$ \\
\hline Fz vs. $\mathrm{Cz}$ & $q(92,3)$ & $* *$ & $* *$ \\
\hline Fz vs. Pz & $q(92,3)$ & $* *$ & -- \\
\hline Cz vs. Pz & $q(92,3)$ & -- & * \\
\hline Age $\times$ Site & $F(2,92)$ & $10.82 * *$ & $8.71 * *$ \\
\hline \multicolumn{4}{|c|}{ Simple main effect of Site } \\
\hline Young & $F(2,92)$ & $21.03 * *$ & $5.83 * *$ \\
\hline Old & $F(2,92)$ & $0.39(.68)$ & $11.85 * *$ \\
\hline Block $\times$ Site & $F(4,184)$ & $13.44 * *$ & $2.58 *$ \\
\hline \multicolumn{4}{|c|}{ Simple main effect of Block } \\
\hline $\mathrm{Fz}$ & $q(92,3)$ & $* *$ & $* *$ \\
\hline $\mathrm{Cz}$ & $q(92,3)$ & $* *$ & $* *$ \\
\hline $\mathrm{Pz}$ & $q(92,3)$ & $* *$ & $* *$ \\
\hline Age $\times$ Block $\times$ Site & $F(4,184)$ & $1.01(.41)$ & $0.29(.89)$ \\
\hline
\end{tabular}

$* \mathrm{p}<.05 ; * * \mathrm{p}<.01$. Values in parentheses indicate the original $\mathrm{p}$ value CRT choice reaction task, GST global stop-signal task, SST selective stopsignal task

$q(92,3) .05=3.38 ; q(92,3) .01=4.24$

amplitudes recorded during the stop-signal trials at the $\mathrm{Cz}$ site showed larger N1s for successful than for failed inhibit trials. Main effects of age and interactions with age were not found.

Results of a three-way ANOVA on N1 peak latencies recorded during stop-signal trials showed delayed N1s for failed compared to successful inhibit trials. Main effect of age and interactions with age were not found.

\section{Stop-signal P3 peak amplitude and latency}

Results of a four-way ANOVA (age $\times$ task-block type $\times$ stoptrial type $\times$ electrode site $[\mathrm{Fz}, \mathrm{Cz}, \mathrm{Pz}])$ of $\mathrm{P} 3$ peak amplitudes recorded during stop trials showed significant main effects of age (reduced P3s among older adults), task-block type (larger P3s in the GST blocks), stop-trial type (larger P3s in successful trials), and electrode site (larger P3s at the $\mathrm{Cz}$ site). Moreover, a significant two-way interaction between age and electrode site was found. Simple effect tests on the interaction showed that a significant main effect of electrode site for both groups.
Results of four-way ANOVAs of P3 peak latencies recorded during stop trials showed significant main effects of age (delayed P3s among older adults), task-block type (delayed $\mathrm{P} 3 \mathrm{~s}$ in the SST blocks), stop-trial type (delayed P3s in failed inhibit trials), and electrode site (delayed P3s at the Pz site). Interactions with age were not found.

\section{Discussion}

This study was designed to examine age-related differences in reactive and proactive inhibitory control by means of measuring both behavioral and ERP data. To consider the three potential factors (i.e., task demand, type of inhibitory control, and age-related compensation) that might contribute to the equivocal results in the literature regarding age-related inhibition deficits, we aimed to delineate if the elderly suffered from either generalized or specific reactive inhibitory control deficits or proactive inhibitory control deficits. We also aimed to determine if they are accompanied by compensation ERP responses associated with reactive and/or proactive inhibitory control when performing stop-signal tasks.

Age-related deficits in reactive inhibitory control were examined by measuring behavioral SSRTs and the ERPs time-locked to the stop-signal trials. Further comparisons were made to elucidate whether age-related differences in SSRTs were similar (suggesting a general deficit) or different (suggesting a specific deficit) between the GST and SST blocks. Behavioral results revealed that older adults exhibited longer SSRTs compared with younger adults, suggesting an age-related decline in reactive inhibitory control, as has been reported by some researchers (e.g., Kleerekooper et al., 2016; Van de Laar et al. 2011). We further observed that age-related differences in SSRTs were similar between the GST and SST blocks, suggesting a general age-related decline in reactive inhibitory control. Moreover, both age groups exhibited the same SSRT differences between the GST and SST blocks (i.e., global stopping was faster than selective stopping). Longer SSRTs in the SST blocks could have resulted from the lower probability of stopping than in the GST blocks. A lower probability of stopping has often been associated with faster responses in GO trials (e.g., Luce, 1986 with go/no-go paradigms; Ramautar, Kok, \& Ridderinkhof, 2004; Van de Laar et al. 2010 with stop-signal task). The current supporting evidence comes from the SSRTs, which were longer in the SST blocks than in the GST blocks. This suggests that the GO trials had a greater influence in the SST than GST blocks. This makes it more difficult in the SST blocks to withhold the response tendency on stop trials. However, as pointed out by van de Laar et al. (2011), SSRT did not necessarily change in 


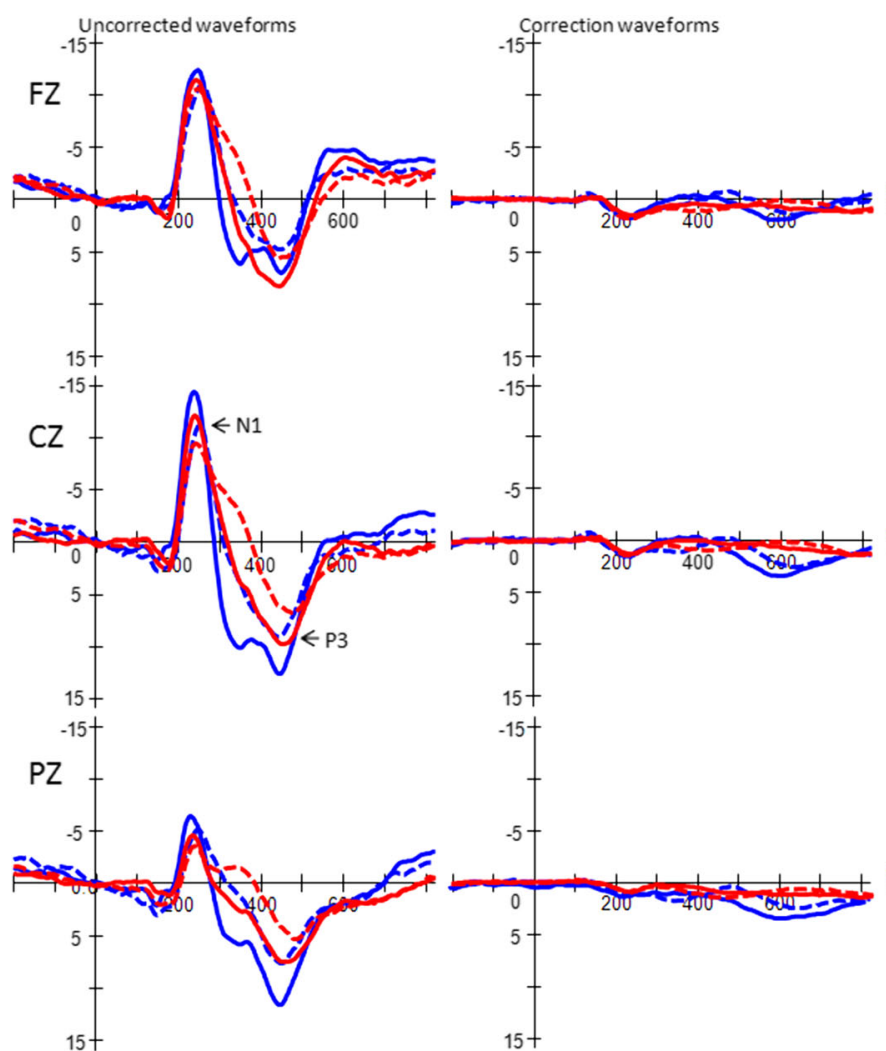

Fig. 3 Grand average event-related potential (ERP) waveforms time locked to the onset of stop signal for younger (blue) and older (red) adults in the global stopping (GST) blocks for the successful inhibit (solid line) and failed inhibit (dotted line) trials at the $\mathrm{Fz}, \mathrm{Cz}$, and $\mathrm{Pz}$ sites. The left column shows original uncorrected ERP waveforms, the

studies manipulating stop-signal probability (Ramautar et al., 2004; van de Laar et al., 2010). Therefore, the difference in SSRT could instead be attributed to the additional decisional component or the use of a selective stopping mechanism with extra demands on signal discrimination, as suggested by Verbruggen and Logan (2009b).

Regarding the ERPs of reactive inhibitory control, no evidence of an age effect was found for the stop-signal N1 when evaluating the ERPs of the stop-signal trials. It has been hypothesized that the N1 peak amplitude reflects the sensitivity of selective attention, which was found to be enhanced on successful inhibit trials (Bekker et al., 2005; Hillyard, Hink, Schwent, \& Picton, 1973; Näätänen \& Michie 1979; Parasuraman, 1980). Hence, our results suggest that the behavioral finding of age-related decline in reactive inhibitory control might not be the result of age-related differences in the sensitivity of selective attention. On the other hand, there was an effect of age on the stop-signal P3 (i.e., it was reduced among the elderly and in the GST and SST blocks). It has been suggested that this peak reflects the efficacy of motor inhibition (stopping process; De Jong et al., 1990; Kok et al., 2004; Polich, 2007); hence, our stop-signal P3 finding

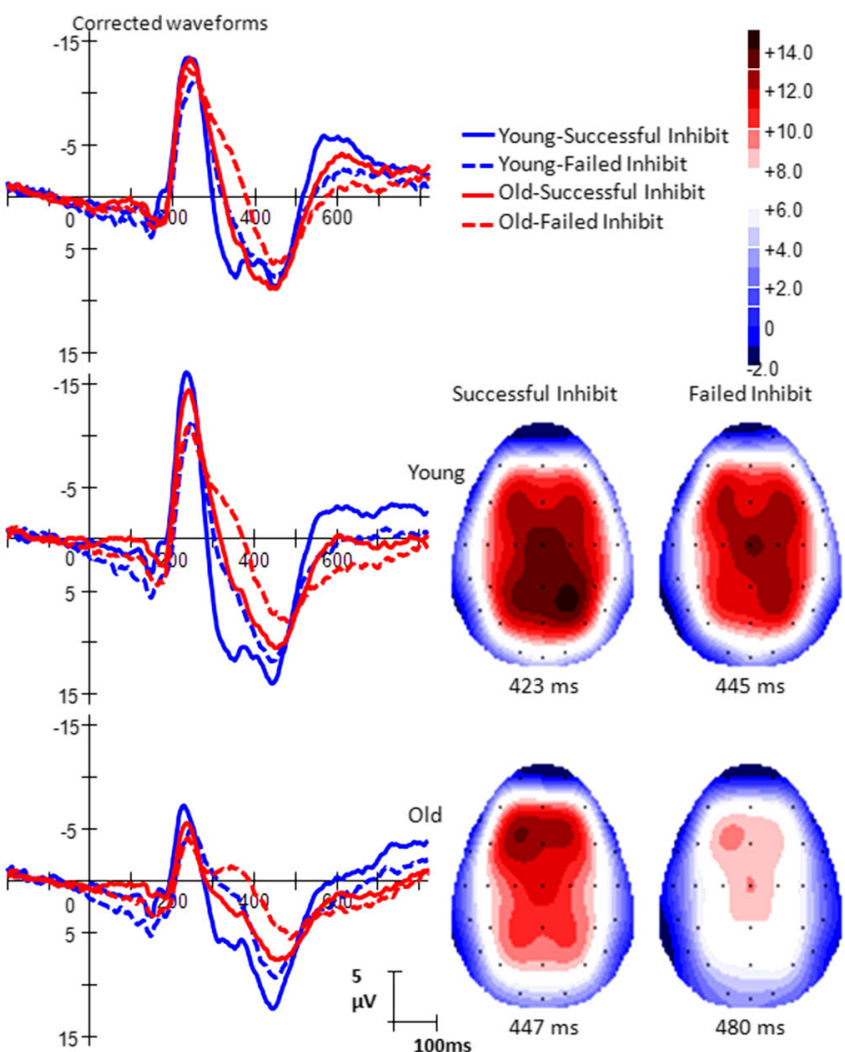

middle column shows ADJAR (adjacent response) correction waveforms, and the right column shows ADJAR-corrected ERP waveforms. The lower right panel shows topographic maps for younger (upper) and older (lower) adults at the $\mathrm{P} 3$ peak latencies of the successful and failed inhibit trials in the GST blocks

agrees with the behavioral SSRT finding, suggesting a general age-related decline in reactive inhibition.

We also observed an age-related delayed P3, likewise suggesting a general age-related decline in reactive inhibitory control. Therefore, the P3 latency finding seems to suggest that age-related deficits in reactive inhibitory control were associated with prolonged processing time of the stop-signal stimulus among the elderly. Although we failed to observe a significant correlation between P3 latency and SSRT, this interpretation can be indirectly supported by another aspect of the behavioral data in which older adults exhibited more omission errors than younger adults during the GO trials across all blocks. Older adults also made more omission errors in the ignored stopsignal trials in the SST blocks, suggesting that they might slow their responses in general so that they can increase performance accuracy (all the correlations between the GO RTs and omission errors reached significance). This hypothesis is supported by the generally slower GO RTs among older adults than younger adults. Slower RTs among older adults have been documented in the aging literature (e.g., Godefroy, Roussel, Despretz, Quaglino, \& Boucart, 2010; Kramer et al., 1994; Lu et al., 2011; May \& Hasher, 1998; Salthouse, 2000; Woods, Wyma, Yund, Herron, \& Reed, 2015). Hence, our 


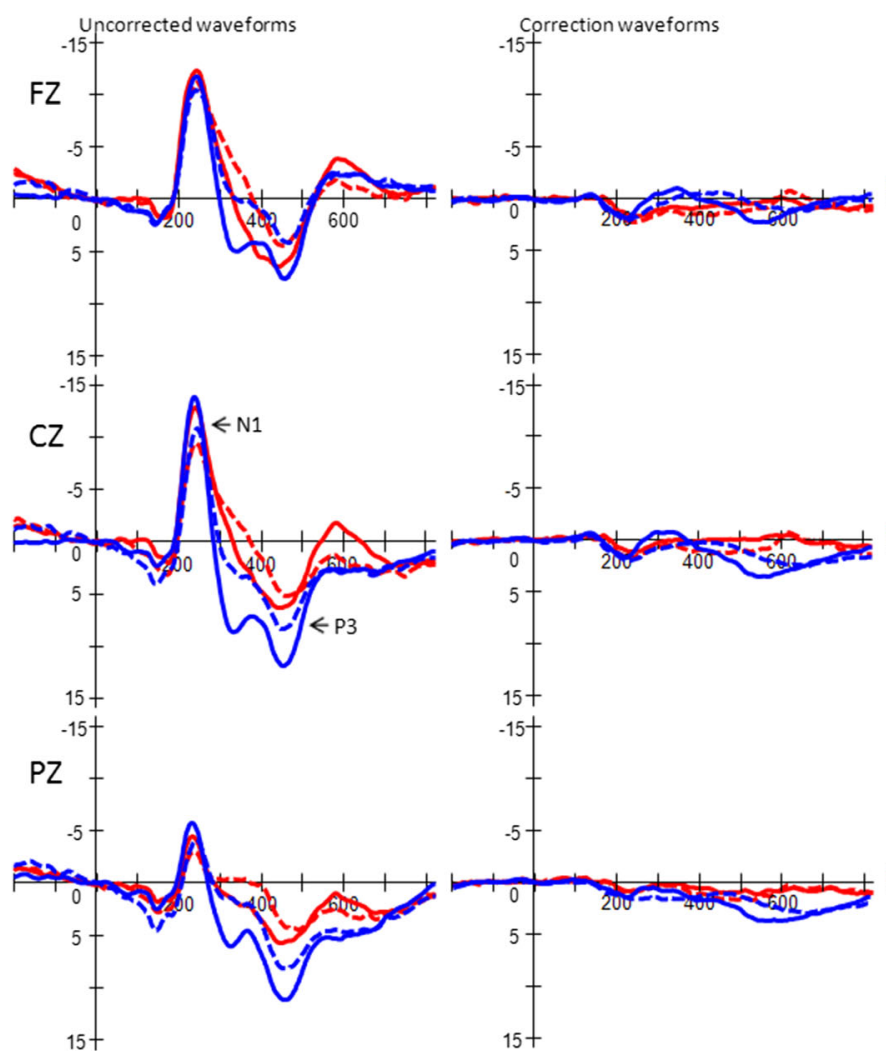

Fig. 4 Grand average event-related potential (ERP) waveforms time locked to the onset of stop signal for younger (blue) and older (red) adults in the selective stopping (SST) blocks for the successful inhibit (solid line) and failed inhibit (dotted line) trials at the $\mathrm{Fz}, \mathrm{Cz}$, and $\mathrm{Pz}$ sites. The left column shows original uncorrected ERP waveforms, the middle

key finding of age-related declines in reactive inhibitory control could be based on the elderly attempting to maintain stopping accuracy by strategically slowing down their responses in general (i.e., speed-accuracy tradeoff; Forstmann et al. 2011; Rabbitt, 1979; Ratcliff, Thapar, and McKoon 2007; Salthouse, 1979; Smith \& Brewer, 1985; 1995; Starns \& Ratcliff, 2010), thereby resulting in slower GO RTs and longer SSRTs as well as higher omissions.

To elucidate whether there are also age-related declines in proactive inhibitory control, we compared the age groups' RTs and ERPs during the GO trials in the CRT blocks versus those in the blocks with stopping signals (the GST and SST blocks). In contrast to age-related declines in reactive inhibitory control, we did not observe behavioral age-related differences in proactive inhibitory control (i.e., anticipation of stopping), which was measured by RT differences during the GO trials between the CRT blocks and the blocks with stopping signals. We found that RT differences were similar between the two age groups. Therefore, our behavioral findings appear to echo a recent neuroimaging study reported by Kleerekooper et al. (2016): These authors did not observe a decline in proactive inhibitory control among older adults but noticed an agerelated deficit (i.e., longer SSRTs) in reactive inhibitory

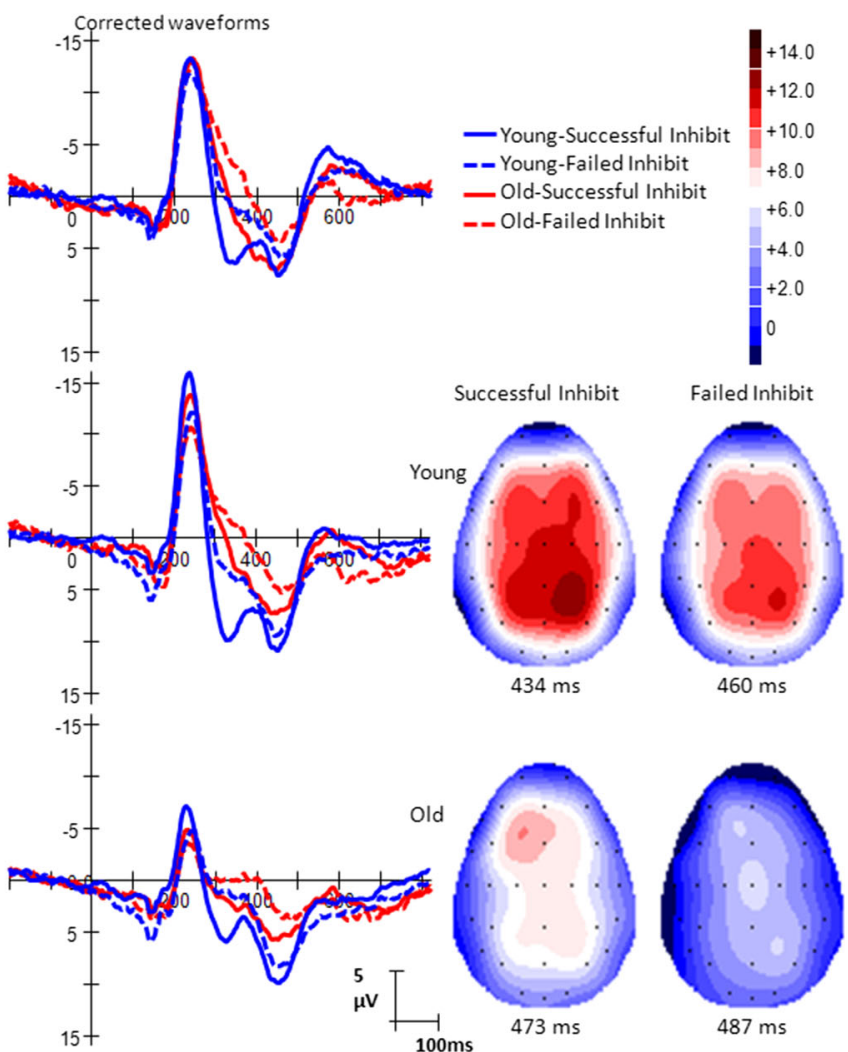

column shows ADJAR (adjacent response) correction waveforms, and the right column shows ADJAR-corrected ERP waveforms. The lower right panel shows topographic maps for younger (upper) and older (lower) adults at the P3 peak latencies of the successful and failed inhibit trials in the SST blocks

control. Nevertheless, Kleerekooper et al. (2016) discovered an age-related compensatory response (i.e., overall hyperactivation) in the rIFG related to adequate proactive inhibitory control among the elderly. This overall hyperactivation is believed to compensate for age-related decreases in flexibility in the rIFG, which showed no differential activations in response

Table 6 Results of the analysis of variance (ANOVA) for the eventrelated potential (ERP) data of the $\mathrm{N} 1$ component at the $\mathrm{Cz}$ site (amplitude and latency) on the stop-signal (successful vs. failed inhibit) trials

\begin{tabular}{llll}
\hline Age $\times$ Block $\times$ Type & & N1 amplitude & N1 latency \\
\hline Stop-signal N1 & & & \\
$\quad$ Age & $F(1,46)$ & $1.31(.26)$ & $0.38(.54)$ \\
Block & $F(1,46)$ & $1.56(.22)$ & $1.24(.27)$ \\
Age $\times$ Block & $F(1,46)$ & $0(1)$ & $0.14(.71)$ \\
Type & $F(1,46)$ & $38.18 * *$ & $15.03 * *$ \\
Age $\times$ Type & $F(1,46)$ & $0.36(.55)$ & $2.07(.16)$ \\
Block $\times$ Type & $F(1,46)$ & $0.65(.43)$ & $0.02(.90)$ \\
Age $\times$ Block $\times$ Type & $F(1,46)$ & $0.24(.63)$ & $0.14(.71)$ \\
\hline
\end{tabular}

$* * \mathrm{p}<.01$. Values in parentheses indicate the original $\mathrm{p}$ value 
Table 7 Results of the analysis of variance (ANOVA) for the eventrelated potential (ERP) data of the $\mathrm{P} 3$ component at the $\mathrm{Fz}, \mathrm{Cz}$, and $\mathrm{Pz}$ sites (amplitude and latency) on the stop-signal (successful vs. failed inhibit) trials

\begin{tabular}{|c|c|c|c|}
\hline $\begin{array}{l}\text { Age } \times \text { Block } \times \text { Type } \\
\times \text { Site }(F Z, C Z, P Z)\end{array}$ & & $\begin{array}{l}\text { Stop P3 } \\
\text { amplitude }\end{array}$ & $\begin{array}{l}\text { Stop P3 } \\
\text { latency }\end{array}$ \\
\hline \multicolumn{4}{|l|}{ Stop-signal P3 } \\
\hline Age & $F(1,46)$ & $7.09 *$ & $13.98 * *$ \\
\hline Block & $F(1,46)$ & $14.43 * *$ & $6.00 *$ \\
\hline Age $\times$ Block & $F(1,46)$ & $1.23(.27)$ & $0.09(.76)$ \\
\hline Type & $F(1,46)$ & $24.42 * *$ & $16.82 * *$ \\
\hline Age $\times$ Type & $F(1,46)$ & $3.10(.08)$ & $0.00(1)$ \\
\hline Block $\times$ Type & $F(1,46)$ & $0.07(.79)$ & $0.38(.54)$ \\
\hline Age $\times$ Block $\times$ Type & $F(1,46)$ & $0.05(.82)$ & $0.91(.35)$ \\
\hline Site & $F(2,92)$ & $32.05 * *$ & $13.50 * *$ \\
\hline Fz vs. $\mathrm{Cz}$ & $q(92,3)$ & $* *$ & -- \\
\hline Fz vs. Pz & $q(92,3)$ & -- & $* *$ \\
\hline $\mathrm{Cz}$ vs. $\mathrm{Pz}$ & $q(92,3)$ & $* *$ & $* *$ \\
\hline Age $\times$ Site & $F(2,92)$ & $9.91 * *$ & $2.01(.14)$ \\
\hline \multicolumn{4}{|l|}{ Simple main effect of Site } \\
\hline Young & $F(2,92)$ & $28.17 * *$ & - \\
\hline Old & $F(2,92)$ & $13.79 * *$ & - \\
\hline Block $\times$ Site & $F(2,92)$ & $8.61 * *$ & $0.09(.91)$ \\
\hline Age $\times$ Block $\times$ Site & $F(2,92)$ & $0.32(.72)$ & $0.81(.45)$ \\
\hline Type $\times$ Site & $F(2,92)$ & $0.12(.88)$ & $3.42 *$ \\
\hline Age $\times$ Type $\times$ Site & $F(2,92)$ & $3.03(.053)$ & $2.14(.12)$ \\
\hline Block $\times$ Type $\times$ Site & $F(2,92)$ & $12.12 * *$ & $1.72(.21)$ \\
\hline Age $\times$ Block $\times$ Type $\times$ Site & $F(2,92)$ & $1.39(.26)$ & $2.06(.13)$ \\
\hline
\end{tabular}

$* \mathrm{p}<.05 ; * * \mathrm{p}<.01$. Values in parentheses indicate the original $\mathrm{p}$ value $q(92,3) .05=3.38 ; q(92,3) .01=4.24$

to varying stop-signal probabilities. Therefore, it is worth examining whether the current ERP data would likewise exhibit age-related neural compensation associated with the seemingly adequate proactive inhibitory control among older adults.

Our ERP results of the GO trials showed reduced N1s (at the P7/P8 sites) in the GST and SST blocks relative to the CRT blocks, yielding ERP evidence of proactive inhibitory control. They also show reduced P3s in the GST and SST blocks relative to the CRT blocks, also yielding ERP evidence of proactive inhibitory control. However, ERP evidence of proactive inhibitory control showed no further interactions with age, suggesting no age-related deficit in proactive inhibitory control.

It has been hypothesized that the N1 peak amplitude is associated with visual attention, where larger amplitudes would be seen for attended stimuli rather than unattended stimuli (Vogel \& Luck, 2000). Hence, the finding that N1 peak amplitudes during GO trials were larger in the CRT blocks than in the GST and SST blocks suggests that participants devoted a different degree of their visual attention to the GO trials in different task blocks. On the other hand, studies in the literature suggest that GO P3 amplitudes reflect the endogenous component that is modulated by the stimulus intensity (Donchin et al., 1986a, b; Jodo \& Inoue, 1990; Polich \& Kok, 1995) or demands on "perceptual-central" resources (see Donchin et al., 1986b; Kramer \& Spinks, 1991). Because the GO trials in the CRT blocks were not intervened by a stop signal, they yielded stronger stimulus intensities and/or perceptual-central resources. In contrast, although the GO trials in the SST and GST blocks did not contain stop signals per se, they were nevertheless embedded in the same block with stop trials, and this might have caused distractions for participants, diminishing focus on the GO stimuli, resulting in smaller amplitudes.

A more interesting finding is the age effect on GO P3 peak amplitudes. While for younger adults the peak amplitudes on the GO trials were larger at the $\mathrm{Cz}$ and Pz sites than the Fz site, for older adults they did not differ significantly among the three electrode sites. This phenomenon (i.e., no differences in amplitudes among the three electrode sites) is consistent with the age-related de-differentiation effect (Li \& Lindenberger, 1999) or seemingly implies age-related compensation (Cabeza \& Dennis, 2012; Davis, Dennis, Daselaar, Fleck, \& Cabeza, 2008).To further clarify if the increased Fz activation for older adults represented a de-differentiation or compensation effect, we examined the correlation between $\mathrm{P} 3$ peak amplitude at the Fz site and the RT of proactive inhibitory control. The correlation was significant and negative specifically for older adults, showing that larger RT differences (reflecting proactive inhibitory control) were associated with

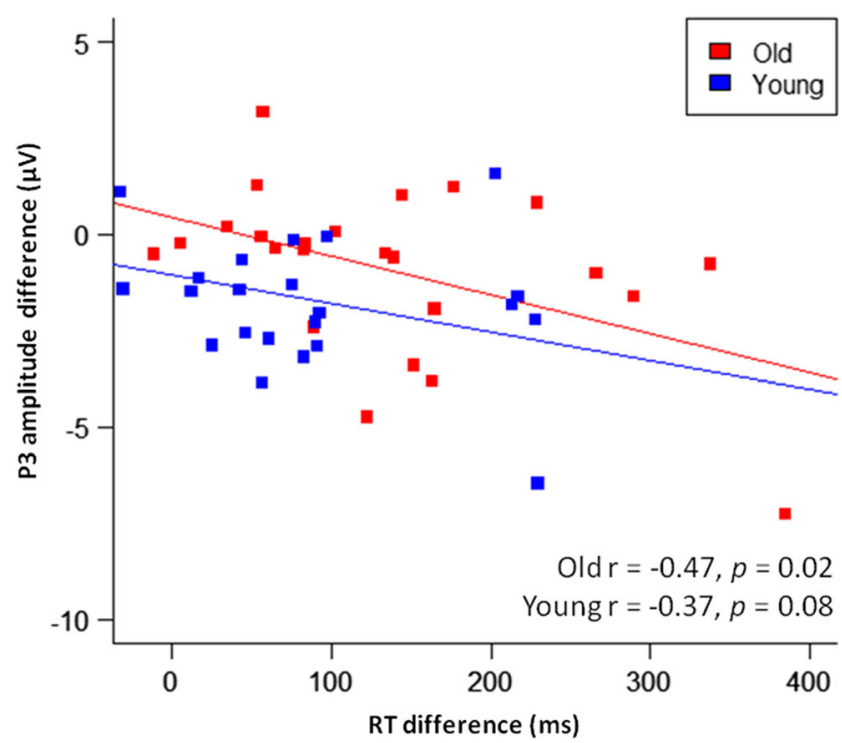

Fig. 5 A scatterplot with two regression fitting lines, one for younger adults (blue), the other for older adults (red), between the P3 amplitude at the Fz site and the reaction time (RT) of proactive inhibitory control (i.e., the P3/RT difference for GO trials between the stop-signal blocks and pure choice task blocks 
larger reductions in P3 amplitudes in the stop-signal blocks relative to the pure choice blocks. Therefore, our results appear to support the age-related compensation hypothesis.

To summarize, this study replicated the behavioral findings that have reported: (i) a general slowing among the elderly (van de Laar et al., 2011), (ii) slower SSRTs among the elderly in both the GST and SST blocks, indicating a general agerelated decline in reactive inhibitory control (Kleerekooper et al., 2016; van de Laar et al., 2011), and (iii) both age groups exhibited equivalent proactive control effects in which they slowed their responses when anticipating a stop signal, as in the GST and SST blocks (Kleerekooper et al., 2016; Logan \& Burkell, 1986; Verbruggen \& Logan, 2008; Vink et al., 2005). More importantly, this study provides additional information about age-related differences in motor inhibition by means of ERP measures. The current stop-signal P3 finding agrees with the behavioral SSRT finding, suggesting a general age-related decline in reactive inhibition. On the other hand, the current GO-N1 and GO-P3 findings were in line with the behavioral results showing no age-related deficits in proactive inhibition. Nevertheless, the current ERP result further reveals agerelated $\mathrm{P} 3$ compensation associated with proactive inhibitory control. Such results are partially consistent with previous findings using other forms of inhibition tasks, such as the Eriksen flanker task (Hsieh \& Fang, 2012; Hsieh, Liang, \& Tsai, 2012; Hsieh \& Lin, 2014) and the go/no-go paradigm (Hsieh, Wu, \& Tang 2016a, b). These studies noted that the elderly did not exhibit impairment in these two forms of inhibition. Instead, they exhibited compensatory responses to cope with their decreased inhibition functions.

The implication of this study is that older adults utilize a speed-accuracy tradeoff response in performing a stop-signal task which might contribute to their deficit in reactive inhibitory control. On the other hand, their behavior is coupled with some forms of brain compensation, such as increasing activation at the frontal site, resulting in no difference when compared with younger adults. A lack of difference is also found when electrode sites are compared, further indicating brain compensation, which might subsequently alleviate older adults' deficiencies in proactive inhibitory control. This finding is consistent with the neural compensation theory and the STAC-r (Park \& Reuter-Lorenz, 2009; Reuter-Lorenz \& Park, 2014), which suggests that older adults compensate for agerelated neural challenges by engaging supplementary neural circuits to preserve cognitive function.

\footnotetext{
Acknowledgments We would like to thank the Ministry of Science Technology (MOST) of Taiwan, R.O.C., for financially supporting this research (Contract Nos. 101-2410-H-006-046-MY3 and 104-2410-H006-021-MY2). In addition, this research was, in part, supported by the Ministry of Education, Taiwan, R.O.C., and The Aim for the Top University Project to the National Cheng Kung University (NCKU).

We also wish to thank American Manuscript Editors (AmericanManuscriptEditors.com) for English proofreading, the action
}

editor and three reviewers who greatly improved the manuscript through their comments, and Chun-Hao Wang for his great help during the revision process.

\section{References}

Anguera, J. A., \& Gazzaley, A. (2012). Dissociation of motor and sensory inhibition processes in normal aging. Clinical Neurophysiology, 123(4), 730-740.

Aron, A. R. (2011). From reactive to proactive and selective control: Developing a richer model for stopping inappropriate responses. Biological Psychiatry, 69(12), e55-e68.

Aron, A. R., \& Verbruggen, F. (2008). Stop the presses: Dissociating a selective from a global mechanism for stopping. Psychological Science, 19, 1146-1153.

Band, G. P., Van Der Molen, M. W., \& Logan, G. D. (2003). Horse-race model simulations of the stop-signal procedure. Acta Psychologica, $112(2), 105-142$.

Beck, A. T., Steer, R. A., Ball, R., \& Ranieri, W. F. (1996). Comparison of Beck Depression Inventories-IA and-II in psychiatric outpatients. Journal of Personality Assessment, 67(3), 588-597.

Bedard, A. C., Nichols, S., Barbosa, J. A., Schachar, R., Logan, G. D., \& Tannock, R. (2002). The development of selective inhibitory control across the life span. Developmental Neuropsychology, 21(1), 93-111.

Bekker, E. M., Kenemans, J. L., Hoeksma, M. R., Talsma, D., \& Verbaten, M. N. (2005). The pure electrophysiology of stopping. International Journal of Psychophysiology, 55(2), 191-198.

Cabeza, R., \& Dennis, N. A. (2012). In D. T. Stuss \& R. T. Knight (Eds.), Frontal lobes and aging: Deterioration and compensation (pp. 491505). New York: Oxford University Press.

Coxon, J. P., Goble, D. J., Leunissen, I., Van Impe, A., Wenderoth, N., \& Swinnen, S. P. (2016). Functional brain activation associated with inhibitory control deficits in older adults. Cerebral Cortex, 26(1), 12-22.

Coxon, J. P., Stinear, C. M., \& Byblow, W. (2007). Selective inhibition of movement. Journal of Neurophysiology, 97(3), 2480-2489.

Coxon, J. P., Stinear, C. M., \& Byblow, W. D. (2009). Stop and go: the neural basis of selective movement prevention. Journal of Cognitive Neuroscience, 21(6), 1193-1203.

Coxon, J. P., Van Impe, A., Wenderoth, N., \& Swinnen, S. P. (2012). Aging and inhibitory control of action: Cortico-subthalamic connection strength predicts stopping performance. Journal of Neuroscience, 32(24), 8401-8412.

Davis, S. W., Dennis, N. A., Daselaar, S. M., Fleck, M. S., \& Cabeza, R. (2008). Que PASA? The posterior-anterior shift in aging. Cerebral Cortex, 18, 1201-1209.

De Jong, R., Coles, M. G., Logan, G. D., \& Gratton, G. (1990). In search of the point of no return: The control of response processes. Journal of Experimental Psychology: Human Perception and Performance, 16(1), 164.

De Jong, R., Coles, M. G., \& Logan, G. D. (1995). Strategies and mechanisms in nonselective and selective inhibitory motor control. Journal of Experimental Psychology: Human Perception and Performance, 21(3), 498.

Donchin, E., Karis, D., Bashore, T., Coles, M., \& Gratton, G. (1986). Cognitive psychophysiology and human information processing. In M. G. H. Coles, E. Donchin, \& S. Porges (Eds.), Psychophysiology: Systems, processes, and applications. New York: Guilford Press.

Donchin, E., Kramer, A., \& Wickens, C. (1986). Applications of eventrelated brain potentials to problems in engineering psychology. Psychophysiology: Systems, processes, and applications. New York: Guilford Press. 
Folstein, M. F., Folstein, S. E., \& McHugh, P. R. (1975). "Mini-mental state": A practical method for grading the cognitive state of patients for the clinician. Journal of Psychiatric Research, 12, 189-198.

Forstmann, B. U., Tittgemeyer, M., Wagenmakers, E.-J., Derrfuss, J., Imperati, D., \& Brown, S. (2011). The speed-accuracy tradeoff in the elderly brain: A structural model-based approach. Journal of Neuroscience, 31, 17242-17249.

Godefroy, O., Roussel, M., Despretz, P., Quaglino, V., \& Boucart, M. (2010). Age-related slowing: Perceptuomotor, decision, or attention decline? Experimental Aging Research, 36(2), 169-89.

Heuninckx, S., Wenderoth, N., \& Swinnen, S. P. (2008). Systems neuroplasticity in the aging brain: Recruiting additional neural resources for successful motor performance in elderly persons. Journal of Neuroscience, 28, 91-99.

Hillyard, S. A., Hink, R. F., Schwent, V. L., \& Picton, T. W. (1973). Electrical signs of selective attention in the human brain. Science, 182(4108), 177-180.

Howell, D. C. (2010). Statistical methods for psychology (7th ed.). Belmont: Thomson Wadsworth.

Hsieh, S., \& Fang, W. (2012). Elderly adults through compensatory responses can be just as capable as young adults in inhibiting the flanker influence. Biological Psychology, 90(2), 113-126.

Hsieh, S., Liang, Y. C., \& Tsai, Y. C. (2012). Do age-related changes contribute to the flanker effect? Clinical Neurophysiology, 123(5), 960-972.

Hsieh, S., \& Lin, Y. C. (2014). The boundary condition for observing compensatory responses by the elderly in a flanker-task paradigm. Biological Psychology, 103, 69-82.

Hsieh, S., Wu, M., \& Tang, C. H. (2016a). Inhibiting prepotent responses in the elderly: Distraction and disinhibition. Cognitive, Affective, \& Behavioral Neuroscience, 16, 124-134.

Hsieh, S., Wu, M., \& Tang, C. H. (2016a). Adaptive strategies for the elderly in inhibiting irrelevant and conflict no-go trials while performing the go/no-go task. Frontiers in Aging Neuroscience 7.

Jodo, E., \& Inoue, K. (1990). Effects of practice on the P300 in a Go/ NoGo task. Electroencephalography and Clinical Neurophysiology, 76(3), 249-257.

Kleerekooper, I., van Rooij, S. J., van den Wildenberg, W. P., de Leeuw, M., Kahn, R. S., \& Vink, M. (2016). The effect of aging on frontostriatal reactive and proactive inhibitory control. NeuroImage, 132, $51-58$.

Kok, A., Ramautar, J. R., De Ruiter, M. B., Band, G. P., \& Ridderinkhof, K. R. (2004). ERP components associated with successful and unsuccessful stopping in a stop-signal task. Psychophysiology, 41(1), 9-20.

Kramer, A. F., Humphrey, D. G., Larish, J. F., \& Logan, G. D. (1994). Aging and inhibition: Beyond a unitary view of inhibitory processing in attention. Psychology and Aging, 9, 491-512.

Kramer, A., \& Spinks, J. (1991). Capacity views of human information processing.

Kray, J., Kipp, K. H., \& Karbach, J. (2009). The development of selective inhibitory control: The influence of verbal labeling. Acta Psychologica, 130(1), 48-57.

Levitt, H. C. C. H. (1971). Transformed up-down methods in psychoacoustics. The Journal of the Acoustical Society of America, 49(2B), 467-477.

Li, S. C., \& Lindenberger, U. (1999). Cross-level unification: A computational exploration of the link between deterioration of neurotransmitter systems and dedifferentiation of cognitive abilities in old age. In L. G. Nilsson \& H. J. Markowitsch (Eds.), Cognitive neuroscience of memory (pp. 103-146). Kirkland: Hogrefe \& Huber.

Logan, G. D., \& Burkell, J. (1986). Dependence and independence in responding to double stimulation: A comparison of stop, change, and dual-task paradigms. Journal of Experimental Psychology: Human Perception and Performance, 12(4), 549.
Logan, G. D., \& Cowan, W. B. (1984). On the ability to inhibit thought and action: A theory of an act of control. Psychological Review, 91, 295-327.

Lu, P. H., Lee, G. J., Raven, E. P., Tingus, K., Khoo, T., Thompson, P. M., \& Bartzokis, G. (2011). Age-related slowing in cognitive processing speed is associated with myelin integrity in a very healthy elderly sample. Journal of Clinical and Experimental Neuropsychology, 33(10), 1059-68.

Luce, R. D. (1986). Response times: Their role in inferring elementary mental organization. New York: Oxford University Press.

May, C. P., \& Hasher, L. (1998). Synchrony effects in inhibitory control over thought and action. Journal of Experimental Psychology: Human Perception and Performance, 24(2), 363.

Näätänen, R., \& Michie, P. T. (1979). Early selective-attention effects on the evoked potential: a critical review and reinterpretation. Biological Psychology, 8(2), 81-136.

Näätänen, R., \& Picton, T. (1987). The N1 wave of the human electric and magnetic response to sound: A review and an analysis of the component structure. Psychophysiology, 24(4), 375-425.

Nasreddine, Z. S., Phillips, N. A., Bédirian, V., Charbonneau, S., Whitehead, V., Collin, I., \& Chertkow, H. (2005). The Montreal Cognitive Assessment, MoCA: A brief screening tool for mild cognitive impairment. Journal of the American Geriatrics Society, 53(4), 695-699.

Parasuraman, R. (1980). Effects of information processing demands on slow negative shift latencies and N100 amplitude in selective and divided attention. Biological Psychology, 11(3), 217-233.

Park, D. C., \& Reuter-Lorenz, P. (2009). The adaptive brain: Aging and neurocognitive scaffolding. Annual Review of Psychology, 60(1), 173-196.

Polich, J. (2007). Updating P300: An integrative theory of P3a and P3b. Clinical Neurophysiology, 118(10), 2128-2148.

Polich, J., \& Kok, A. (1995). Cognitive and biological determinants of P300: An integrative review. Biological Psychology, 41(2), 103-146.

Rabbitt, P. (1979). How old and young subjects monitor and control responses for accuracy and speed. British Journal of Psychology, $70,305-311$.

Ramautar, J. R., Kok, A., \& Ridderinkhof, K. R. (2004). Effects of stopsignal probability in the stop-signal paradigm: The N2/P3 complex further validated. Brain and Cognition, 56(2), 234-52.

Ratcliff, R., Thapar, A., \& McKoon, G. (2007). Application of the diffusion model to two-choice tasks for adults 75-90 years old. Psychology and Aging, 22, 56-66.

Reuter-Lorenz, P. A., \& Park, D. C. (2014). How does it STAC up? Revisiting the scaffolding theory of aging and cognition. Neuropsychology Review, 24(3), 355-370.

Salthouse, T. (1979). Adult age and the speed-accuracy trade-off. Ergonomics, 22, 811-821.

Salthouse, T. A. (2000). Aging and measures of processing speed. Biological Psychology, 54, 35-54.

Schmajuk, M., Liotti, M., Busse, L., \& Woldorff, M. G. (2006). Electrophysiological activity underlying inhibitory control processes in normal adults. Neuropsychologia, 44, 384-395.

Sharp, D. J., Bonnelle, V., De Boissezon, X., Beckmann, C. F., James, S. G., Patel, M. C., \& Mehta, M. A. (2010). Distinct frontal systems for response inhibition, attentional capture, and error processing. Proceedings of the National Academy of Sciences of the United States of America, 107, 6106-6111.

Smith, G. A., \& Brewer, N. (1985). Age and individual differences in correct and error reaction times. British Journal of Psychology, 76, 199-203.

Smith, G. A., \& Brewer, N. (1995). Slowness and age: Speed-accuracy mechanisms. Psychology and Aging, 10, 238-247.

Smittenaar, P., Rutledge, R. B., Zeidman, P., Adams, R. A., Brown, H., Lewis, G., \& Dolan, R. J. (2015). Proactive and reactive response inhibition across the lifespan. PLOS ONE, 10(10), e0140383. 
Starns, J. J., \& Ratcliff, R. (2010). The effects of aging on the speedaccuracy compromise: Boundary optimality in the diffusion model. Psychology and Aging, 25, 377-390.

Stinear, C. M., Coxon, J. P., \& Byblow, W. D. (2009). Primary motor cortex and movement prevention: Where Stop meets go. Neuroscience and Biobehavioral Reviews, 33(5), 662-673.

Van de Laar, M. C., Wildenberg, W. P. M., Boxtel, G. J. M., \& Molen, M. W. (2010). Processing of global and selective stop signals: Application of Donders' subtraction method to stop-signal task performance. Experimental Psychology, 57(2), 149-59.

Van de Laar, M. C., Wildenberg, W. P. M., Boxtel, G. J. M., \& Molen, M. W. (2011). Lifespan changes in global and selective stopping and performance adjustments. Frontiers in Psychology, 2, 375.

Verbruggen, F., \& Logan, G. D. (2008). Response inhibition in the stopsignal paradigm. Trends in Cognitive Sciences, 12(11), 418-424.

Verbruggen, F., \& Logan, G. D. (2009a). Models of response inhibition in the stop-signal and stop-change paradigms. Neuroscience \& Biobehavioral Reviews, 33, 647-661.

Verbruggen, F., \& Logan, G. D. (2009b). Proactive adjustments of response strategies in the stop-signal paradigm. Journal of Experimental Psychology: Human Perception and Performance, 35(3), 835-54.
Vink, M., Kahn, R. S., Raemaekers, M., van den Heuvel, M., Boersma, M., \& Ramsey, N. F. (2005). Function of striatum beyond inhibition and execution of motor responses. Human Brain Mapping, 25(3), 336-344.

Vogel, E. K., \& Luck, S. J. (2000). The visual N1 component as an index of a discrimination process. Psychophysiology, 37(02), 190-203.

Williams, B. R., Ponesse, J. S., Schachar, R. J., Logan, G. D., \& Tannock, R. (1999). Development of inhibitory control across the life span. Developmental Psychology, 35(1), 205-213.

Woldorff, M. G. (1993). Distortion of ERP averages due to overlap from temporally adjacent ERPs: Analysis and correction. Psychophysiology, 30, 98-119.

Woods, D. L., Wyma, J. M., Yund, E. W., Herron, T. J., \& Reed, B. (2015). Age-related slowing of response selection and production in a visual choice reaction time task. Frontiers in Human Neuroscience, 9, 193.

Woody, C. D. (1967). Characterization of an adaptive filter for the analysis of variable latency neuroelectric signals. Medical \& Biological Engineering, 5, 539-553.

Zandbelt, B. B., \& Vink, M. (2010). On the role of the striatum in response inhibition. PloS One, 5(11), e13848. 